\title{
ADUBAÇÃO BIOLÓGICA ASSOCIADA A ADUBAÇÃO QUÍMICA NOS PARÂMETROS DE SOLO, NUTRICIONAL E PRODUTIVO DO MILHO
}

\author{
Rodrigo Caixeta Pinheiro ${ }^{1,3}$, Jéssica de Lima Pereira ${ }^{1,3}$, Cláudia Fabiana Alves Rezende ${ }^{2 *}$
}

\begin{abstract}
RESUMO - Este trabalho teve como objetivo verificar a possibilidade de redução da adubação com o uso de biofertilizante e sua influência nas características químicas do solo, na nutrição foliar e na produtividade na cultura do milho. O estudo foi desenvolvido na Unidade Experimental da UniEvangélica, no município de Anápolis, GO. O experimento foi conduzido em delineamento em blocos casualizados com quatro tratamentos e quatro repetições. Os tratamentos foram T1: sem adubação química (testemunha); T2: $50 \%$ da adubação; T3: 75\% da adubação e T4: 100\% da adubação NPK (400 kg ha-1 05-25-15 + $222 \mathrm{~kg} \mathrm{ha}^{-1}$ uréia em cobertura). Todos os tratamentos receberam a aplicação de $150 \mathrm{~L} \mathrm{ha}^{-1}$ de fertilizante biológico. Procedeu-se à análise de variância, comparando-se as médias dos parâmetros de fertilidade do solo, nutricionais da planta e produção pelo teste de Tukey e as doses de NPK por análise de regressão. A aplicação do biofertilizante permite melhorar o estado nutricional e produtivo da cultura do milho com reflexos positivos na melhora da fertilidade do solo. A adubação biológica com utilização do biofertilizante apresenta-se como uma alternativa a redução no uso de adubação química a partir do segundo ano de uso em áreas de plantio direto. Novos estudos devem ser realizados a fim de verificar se o uso contínuo promove melhoras gradativas na fertilidade dos solos do Cerrado.
\end{abstract}

Palavras chave: bioativação do solo, microgeo $®$, sistema de plantio direto, Zea mays L.

\section{BIOLOGICAL FERTILIZATION ASSOCIATED WITH CHEMICAL FERTILIZATION IN SOIL, NUTRITIONAL AND PRODUCTIVE PARAMETERS OF CORN}

\begin{abstract}
The objective of this work was to verify the possibility of reducing the fertilization with the use of biofertilizer and its influence on soil chemical characteristics, foliar nutrition and corn crop yield. The study was developed at the UniEvangelica Experimental Unit, in the municipality of Anápolis, GO. The experiment was conducted in a randomized complete block design with four treatments and four replicates. The treatments were T1: without chemical fertilization (control); T2: 50\% of the fertilization; T3: 75\% of fertilization and T4: 100\% of NPK fertilization (400 kg ha-1 05-25-15 + $222 \mathrm{~kg} \mathrm{ha}^{-1}$ urea in coverage). All treatments received the application of $150 \mathrm{~L} \mathrm{ha}$-1 of biological fertilizer. The analysis of variance was performed, comparing the means of soil fertility, plant nutritional parameters and Tukey test and NPK rates by regression analysis. The application of the biofertilizer allows to improve the nutritional and productive state of the maize crop with positive reflexes in the improvement of soil fertility. Biological fertilization with the use of biofertilizer is an alternative to the reduction in the use of chemical fertilization from the second year of use in no-tillage areas. New studies should be carried out to verify if continuous use promotes gradual improvements in soil fertility in the Cerrado.
\end{abstract}

Keywords: microgeo ${ }^{\circledR}$, no-tillage system, soil bioactivation, Zea mays L.

\footnotetext{
${ }^{1}$ Bolsista de iniciação científica, graduado(a) em Agronomia da UniEvangélica, Anápolis, GO.

${ }^{2 *}$ Doutora em Agronomia, professora do curso de Agronomia, UniEvangélica, Anápolis, GO. E-mail: claudia7br@msn.com.
} 


\section{INTRODUÇ̃̃O}

O modelo de produção agrícola convencional é economicamente viável, mas é responsável afetar negativamente o meio ambiente e aos indivíduos que o compõe. Surge a necessidade à adoção de novas tecnologias que permitam uma produção equiparável, conservando os recursos naturais e diminuindo os impactos negativos ao meio ambiente (Santos et al., 2017). Deve-se considerar que o fluxo dos nutrientes que estão imobilizados na solução do solo é essencial para a manutenção da fertilidade nos sistemas (Barros \& Liberalino Filho, 2008).

Uma forma de amenizar o impacto negativo dos fertilizantes químico á a utilização dos biofertilizante. Os biofertilizantes constituem uma fonte com potencialidade para aplicação na produção de plantas (Silva et al., 2015). $\mathrm{Na}$ forma líquida, o uso do biofertilizante é assimilado com maior rapidez, tendo grande utilidade para culturas que necessitam de quantidade elevada de nutrientes sistemas (Barros \& Liberalino Filho, 2008).

A aplicação de biofertilizante apesar de sua função primária em fornecer nutrientes, tem sido uma das alternativas utilizadas para mitigar os efeitos da degradação do solo, uma vez que a matéria orgânica atua como agente cimentante entre as partículas, aumenta a capacidade de troca de cátions, disponibilizando mais nutrientes às plantas, e serve como fonte de alimento para a biota do solo (Alencar et al., 2015).

Bellini et al. (2012) trabalhando com arroz e o uso de biofertilizante observaram a manutenção do $\mathrm{pH}$ após a colheita da cultura, incrementando MO e contribuindo para a disponibilização de fósforo $(\mathrm{P})$ no solo, além de ter reduzido a compactação do solo. Araújo e Santos Júnior (2015) relatam que a aplicação de biofertilizantes na cultura do milho promovem no segundo cultivo aumento da disponibilidade de $\mathrm{P}$.

Considerando-se que, quanto maior a capacidade da planta em acumular um nutriente, maiores serão as diferenças na concentração desse nutriente em resposta às taxas variáveis de adubação (Sediyama et al., 2014). Este trabalho objetivou avaliar diferentes doses de adubação química associada ao uso do biofertilizante e sua influência nas características químicas do solo, na nutrição foliar e na produtividade na cultura do milho.

\section{MATERIAL E MÉTODOS}

O estudo foi desenvolvido no município de Anápolis, na Unidade Experimental do Centro
Universitário de Anápolis, UniEvangélica, entre as coordenadas geográficas, Latitude $16^{\circ} 19^{\prime \prime} 36^{\prime}$ S e Longitude $48^{\circ} 27^{\prime}$ ' $10^{\prime} \mathrm{W}$, com altitude $1.030 \mathrm{~m}$. O clima da região é classificado de acordo com Köppen, como Aw (tropical com estação seca) com mínima de $18^{\circ} \mathrm{C}$ e máxima de $32^{\circ} \mathrm{C}$, com chuvas de outubro a abril e precipitação pluviométrica média anual de $1.450 \mathrm{~mm}$ e temperatura média anual de $22{ }^{\circ} \mathrm{C}$. O solo foi classificado como Latossolo Vermelho eutófico cambissólico, com 36\% argila, 19\% silte e 45\% areia, textura argilosa. Foi utilizada a cultivar de milho AS 1757 PRO3.

A área utilizada se encontra em plantio direto, com milho na safra anterior e braquiária na entressafra, sendo o segundo ano de utilização do biofertilizante. Na semana antecedente a semeadura do milho, as plantas daninhas presentes na área foram dessecadas com dicloreto de paraquate (400 $\mathrm{g} \mathrm{ha}^{-1}$ de i.a) e glifosato (1.920 $\mathrm{g} \mathrm{ha}^{-1}$ de i.a.). A semeadura foi realizada no dia 20 de nov. 2017 sob plantio direto, distribuindo-se 4,1 sementes $\mathrm{m}^{-1}$ a uma profundidade de $0,04 \mathrm{~m}$. A emergência das plântulas ocorreu seis dias após a semeadura e a população inicial estabelecida foi de 63.076 plantas $\mathrm{ha}^{-1}$. O experimento foi conduzido em delineamento em blocos casualizados com quatro tratamentos e quatro repetições e cada parcela foi constituída de 10 linhas de $30 \mathrm{~m}$ de comprimento espaçadas $0,65 \mathrm{~m}$, obtendo $195 \mathrm{~m}^{2}$ por parcela.

Foram determinados os seguintes tratamentos: T1: sem adubação química (testemunha); T2: $50 \%$ da adubação; T3: 75\% da adubação e T4: 100\% da adubação NPK (400 kg ha ${ }^{-1}$ 05-25-15 + $222 \mathrm{~kg} \mathrm{ha}^{-1}$ uréia em cobertura). A adubação de plantio foi realizada no sulco e a cobertura foi realizada no estágio V4, 24 dias após emergência. Foi realizada adubação biológica aos 20 dias após emergência da cultura com biofertilizante composto de esterco bovino, água e o produto comercial Microgeo ${ }^{\circledR}$ em todos os tratamentos, com dose de $150 \mathrm{~L}$ ha-1, conforme recomendação do fabricante do biofertilizante.

O controle de plantas daninha foi realizada em pós emergência utilizando glifosato (960 $\mathrm{g} \mathrm{ha}^{-1}$ i.a.), no qual as plantas invasoras estavam em fase inicial de desenvolvimento e o milho em estágio V4. Na fase V6 foi necessária à aplicação de fungicida para controle da ferrugem comum (Puccinia sorghi) utilizando picoxistrobina ( $90 \mathrm{~g} \mathrm{~L} \mathrm{ha}{ }^{-1}$ i.a.) e ciproconazol (36 $\mathrm{g} \mathrm{L} \mathrm{ha}^{-1}$ i.a.). As aplicações foram realizadas através de pulverizador de barras montado com volume de calda de $150 \mathrm{~L} \mathrm{ha}^{-1}$.

Antes do plantio e ao final do ciclo da cultura foram retiradas amostras (quatro amostras tratamento) de solo compostas $(0,0-0,20 \mathrm{~m})$ em cada tratamento com 
auxílio de trado holandês. O solo foi encaminhado ao laboratório e as características químicas determinadas a partir de análises laboratoriais do solo coletado, conforme metodologia proposta por Silva (2009). Com base nas análises, foram calculadas a CTC do solo a saturação por bases (V) e a saturação por alumínio (m).

A avaliação do estado nutricional das plantas de milho foi realizada na época do florescimento pleno (60 DAE). Foram coletadas folhas completamente desenvolvidas, situadas imediatamente abaixo e opostas à primeira espiga. De cada parcela foram retiradas seis repetições de 30 folhas de plantas situadas na área útil da parcela experimental (Malavolta et al., 1989). Essas amostras foram lavadas em água corrente e colocadas em sacos de papel para secagem em estufa. Os teores de nutrientes foliares foram estimados de acordo com as metodologias propostas por Silva (2009). Para a avaliação da massa seca das plantas as amostras foram coletadas no aparecimento da inflorescência feminina, seis amostras por tratamento. Depois de lavadas em água correte, as plantas foram colocadas para secar em estufa a $65{ }^{\circ} \mathrm{C}$, durante $72 \mathrm{~h}$; após este período as amostras foram pesadas para determinar a massa seca da planta.

$\mathrm{Na}$ fase de grão pastoso foram mensuradas 10 plantas por parcela para determinação do diâmetro de colmo (DC diâmetro do segundo internódio, a partir da base da planta), altura de plantas (AP - medição do colo até a inserção da folha "bandeira") e altura de inserção da espiga (AIE - medição do colo até a inserção da primeira espiga viável com o colmo). Os parâmetros DC e AP foram analisados no período vegetativo em V4 (DCv e APv), 24 dias após emergência e no período de floração plena (DCf e APf) 70 dias após emergência. A colheita foi realizada no dia 27 de março de 2018 (122 dias após emergência), realizando avaliação de população final de plantas, comprimento de espiga (CE - base ao ápice), diâmetro de espiga (DE - porção mediana da espiga), número de fileiras de grãos $(\mathrm{FG})$ e número de grãos por fileira $(\mathrm{GF})$, massa de 1.000 grãos (MMG - pesagem de uma subamostra de 100 grãos por parcela).

A determinação da produtividade (PROD) foi realizada pelo método proposto pela Emater-MG, conforme especifica Rodrigues et al. (2005), em que procede a contagem do número de plantas em $10 \mathrm{~m}$ lineares e coleta-se três espigas aleatórias para determinação da média do peso dos grãos das três espigas. Recomenda-se repetir o procedimento dentro do talhão para redução do erro, sendo realizadas duas repetições por parcela, de forma que foram coletadas seis espigas por parcela e 24 espigas por tratamento.
Os resultados foram submetidos a análise de variância (ANAVA), e quando ocorreram diferenças significativas, identificadas pelo teste $\mathrm{F}(\mathrm{P}<0,05)$, se aplicou o teste de médias de Tukey. As médias das doses de nutrientes NPK foram submetidas a análises por regressão, ajustando-se modelos de equações significativas pelo teste F, utilizando-se programa estatístico Sisvar, versão 5.6 (Ferreira, 2014).

\section{RESULTADOS E DISCUSSÃO}

De acordo com os resumos de variância da cultura do milho (Tabela 1), observa-se que os valores de diâmetro de colmo (DC), altura de plantas (AP) e altura de inserção de espigas (AIE) foram influenciados de pelas doses de adubação NPK, com exceção do diâmetro de colmo fase vegetativa (DC1). Os tratamentos com $75 \%$ e $100 \%$ de adubação apresentaram resultados semelhantes estatisticamente, mostrando que a adubação biológica não afetou os parâmetros avaliados com redução de até $25 \%$ da adubação. De acordo com Pariz et al. (2011), a altura de plantas possui grande importância em função de proporcionar maior quantidade de massa fresca e garantir um maior acúmulo de nutrientes para serem translocados aos grãos, o que influencia diretamente na produtividade da cultura.

Na avaliação da massa úmida os tratamentos com doses de adubação foram estatisticamente superiores a testemunha (Tabela 1). Já na massa seca foliar nota-se que o tratamento com $75 \%$ da adubação foi superior aos demais tratamentos. Esta diferenciação no acumulo de massa seca na folha pode ser uma resposta do biofertilizante, que pode ter correspondido melhor na dose de $75 \%$ da adubação e resultado em um melhor aproveitamento dos nutrientes no solo. É possível que as respostas encontradas para as variáveis massa seca de folhas, estejam relacionadas aos elementos existentes no biofertilizante os quais podem, quando adicionados ao solo, provocar interações sinérgicas ou antagônicas conforme a disponibilidade de nutrientes. De acordo com Lima et al. (2012), o uso de biofertilizante bovino tem estimulado a produção de matéria seca da folha, do caule e da parte aérea do milho. Esses resultados também são evidenciados por Rebouças Neto et al. (2016).

A aplicação do biofertilizante na superfície do solo, na dosagem de $150 \mathrm{~L} \mathrm{ha}^{-1}$ alterou as propriedades químicas avaliadas no segundo ano de aplicação (Tabela 2). Os resultados indicam haver interação entre adubação orgânica (biofertilizante) e adubação mineral na melhora 
dos atributos químicos do solo. Quando se compara os parâmetros químicos do segundo ano de uso do biofertilizante com os resultados do primeiro ano, pode se observar um incremento nos valores disponíveis no solo de
P, K, Ca, Mg, CTC e MO. E uma piora no ambiente com relação aos parâmetros de $\mathrm{pH}, \mathrm{H}+\mathrm{Al}, \mathrm{Al} \mathrm{e} \mathrm{V}$, indicando uma maior absorção de nutrientes pelas plantas e acidificação do meio.

Tabela 1 - Valores médios de diâmetro de colmo (DC), altura de planta (AP) e altura de inserção de espiga (AIE), massa úmida (MU) e seca (MS) de plantas em função da aplicação de doses diferentes de adubação NPK em semeadura e cobertura com aplicação de biofertilizante, $150 \mathrm{~L} \mathrm{ha}^{-1}$, na cultura do milho primeira safra (2017/18)

\begin{tabular}{|c|c|c|c|c|c|c|c|}
\hline \multirow{2}{*}{ \% adubação ${ }^{2}$} & $\mathrm{DCv}$ & $\mathrm{DCf}$ & $\mathrm{APv}$ & APf & AIE & $\mathrm{MU}$ & MS \\
\hline & \multicolumn{2}{|c|}{.......... $\mathrm{mm}$.............. } & \multicolumn{3}{|c|}{ 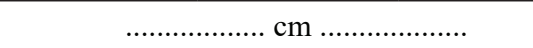 } & \multicolumn{2}{|c|}{ …........... g ............. } \\
\hline 0 & $5,8 \mathrm{a}$ & $17,1 \mathrm{c}$ & $23,0 \mathrm{c}$ & $151,8 \mathrm{c}$ & $56,2 \mathrm{a}$ & $160,9 b$ & $42,9 \mathrm{c}$ \\
\hline 50 & $11,6 \mathrm{a}$ & $19,4 b$ & $32,5 b$ & $181,7 b$ & $78,0 \mathrm{~b}$ & $209,8 \mathrm{a}$ & $58,6 b$ \\
\hline 75 & $11,3 \mathrm{a}$ & $21,2 \mathrm{a}$ & $36,8 \mathrm{a}$ & $190,8 \mathrm{a}$ & $83,5 \mathrm{a}$ & $201,1 \mathrm{a}$ & $76,7 \mathrm{a}$ \\
\hline 100 & $10,9 \mathrm{a}$ & $21,5 \mathrm{a}$ & $39,7 \mathrm{a}$ & $189,7 \mathrm{a}$ & $80,7 \mathrm{ab}$ & $210,1 \mathrm{a}$ & $58,9 \mathrm{~b}$ \\
\hline TesteF $^{1}$ & $0,05 \mathrm{~ns}$ & $0,00 * *$ & $0,00 * *$ & $0,00 * *$ & $0,00 * *$ & $0,00 * *$ & $0,00 * *$ \\
\hline $\mathrm{CV}(\%)$ & 83,68 & 6,71 & 15,99 & 5,27 & 8,84 & 17,83 & 9,27 \\
\hline
\end{tabular}

${ }^{1}$ Teste $\mathrm{F}: * *$ e *significativo a $1 \%$ e $5 \%$ de probabilidade, respectivamente, ns: não significativo; Médias seguidas por mesma letra na coluna, não diferem entre si pelo teste de Tukey a 5\% de probabilidade; CV - coeficiente de variação. 2adubação $100 \%$ referente a $400 \mathrm{~kg}$ ha $^{-1}$ de 05-25-15 + $223 \mathrm{~kg} \mathrm{ha}^{-1}$ de uréia em cobertura; 3DCv e APv - fase vegetativa e DCf e APf - florescimento pleno.

A maior acidificação do solo $(\mathrm{pH})$ ocorre no tratamento com a adubação química completa $(100 \%)$ pode ser explicada pela maior extração pelas plantas (Tabela 2). $\mathrm{O}$ uso de fertilizantes minerais favorece a diminuição dos valores de $\mathrm{pH}$, ocorre à tendência devido ao efeito ácido da nitrificação do amônio.

acidez trocável (Al trocável) devido ao valor de $\mathrm{pH}$ estar próximo de 5,0. A acidez potencial $(\mathrm{H}+\mathrm{Al})$ apresentou comportamento semelhante ao $\mathrm{pH}$, observando-se aumento da concentração de $\mathrm{H}+\mathrm{Al}$ nos diferentes tratamentos, o que não era esperado, pois espera-se uma redução da acidez potencial com o uso do biofertilizante. O maior valor observado está ligado à maior dose de adubação química utilizada (100\% recomendada).

Observa-se aumento nos teores de Ca no solo no segundo ano de uso do biofertilizante. Como não foi realizada a calagem na área no segundo ano de avaliação, o Ca residual no solo deve estar associado a mineralização dos restos culturais, principalmente $\mathrm{K}$ e $\mathrm{Ca}$, contidos na palhada. A disponibilidade de K no solo e a sua absorção pelas plantas está relacionada com a disponibilidade de $\mathrm{Ca}$ e $\mathrm{Mg}$. Observa-se que o incremento nos teores de $\mathrm{K}$ no solo, mesmo com a competição, não diminuíram a presença do $\mathrm{Ca}$ e $\mathrm{Mg}$ nas superfícies sortivas, o que também foi observado por Silva et al. (2008).

Não foi possível verificar o efeito do biofertilizante sobre a Não ocorrem diferenças estatísticas entre os tratamentos no segundo ano, pode se observar na Tabela 2, que ocorre o aumento nos teores de Ca e $\mathrm{K}$ no solo com o uso do biofertilizante. Observa-se relação direta nas concentrações desses elementos no solo, à medida que se observa menores teores de $\mathrm{Ca}$, ocorre um aumento no teor de $\mathrm{K}$ e $\mathrm{Mg}$ e valores de $\mathrm{pH}$ mais elevados com o uso do biofertilizante. Há de se considerar que os efeitos da adubação mineral sobre os teores de $\mathrm{Ca}$ e $\mathrm{Mg}$ trocável no solo deve ser indireto, visto que não foi fornecido $\mathrm{Ca}$ e $\mathrm{Mg}$ via adubação química, pressupõe-se que as concentrações no solo sejam devidas ao uso do biofertilizante.

A saturação por bases foi afetada pela aplicação do biofertilizante, sendo coerente com o observado, o aumento do $\mathrm{pH}$ e dos teores de $\mathrm{Ca}, \mathrm{Mg}$ e $\mathrm{K}$, com a redução da acidez potencial, o que se destaca na testemunha no segundo ano de aplicação. Esse residual apresentado no solo deve ser avaliado junto a baixa produção apresentada pela testemunha, a planta não produtiva também absorve menor quantidade de nutrientes, que não são exportados, ou seja, permanecem no solo após o final do ciclo. A maior redução na saturação por bases observada no tratamento com adubação completa, pode estar associada a maior absorção de nutrientes pelas plantas, aumento da acidez potencial e produção $100 \%$ maior que a apresentada pela testemunha. Para os demais tratamentos o uso de $75 \%$ da adubação química associado ao biofertilizante apresentou as melhore relações dentro do solo. 
Tabela 2 - Características químicas do solo na cultura do milho após o uso de diferentes dosagens de adubação química e biofertilizante, 150 L ha-1 (2017/18)

\begin{tabular}{|c|c|c|c|c|c|}
\hline \multirow{2}{*}{ \% adubação ${ }^{1}$} & $\mathrm{pH}$ & $\mathrm{P}(\mathrm{Mel})$ & $\mathrm{K}$ & $\mathrm{Ca}$ & $\mathrm{Mg}$ \\
\hline & $\left(\mathrm{CaCl}_{2}\right)$ & \multicolumn{2}{|c|}{$\ldots \ldots \ldots \mathrm{mg} \mathrm{dm}^{-3} \ldots \ldots \ldots$} & \multicolumn{2}{|c|}{$\ldots \ldots . \mathrm{cmo}_{\mathrm{c}} \mathrm{dm}^{-3} \ldots \ldots}$. \\
\hline $1^{\circ} \mathrm{ano}^{2}$ & 5,17 a & $0,72 \mathrm{c}$ & $42,75 \mathrm{~b}$ & $2,07 \mathrm{~b}$ & $0,77 \mathrm{c}$ \\
\hline 0 & $5,27 \mathrm{a}$ & $2,1 \mathrm{bc}$ & $93,75 \mathrm{a}$ & $2,87 \mathrm{a}$ & $1,15 \mathrm{a}$ \\
\hline 50 & $5,15 \mathrm{ab}$ & $3,47 \mathrm{~b}$ & $72,45 \mathrm{a}$ & $2,65 \mathrm{a}$ & $0,9 \mathrm{bc}$ \\
\hline 75 & $5,22 \mathrm{a}$ & $3,27 \mathrm{~b}$ & $87,5 \mathrm{a}$ & $3,07 \mathrm{a}$ & $1,05 a b$ \\
\hline 100 & $5,0 \mathrm{~b}$ & $5,75 \mathrm{a}$ & $88,5 \mathrm{a}$ & $2,7 \mathrm{a}$ & $0,82 \mathrm{c}$ \\
\hline Teste F & $0 * *$ & $0,0 * *$ & $0,0 * *$ & $0,0 * *$ & $0,0 * *$ \\
\hline $\mathrm{CV}(\%)$ & 2,88 & 45,63 & 31,4 & 14,77 & 19,06 \\
\hline \multirow{2}{*}{ \% adubação ${ }^{1}$} & $\mathrm{H}+\mathrm{Al}$ & CTC & $\mathrm{Al}$ & MO & $\mathrm{V}$ \\
\hline & \multicolumn{3}{|c|}{ 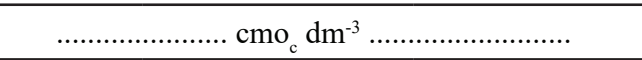 } & \multicolumn{2}{|c|}{ 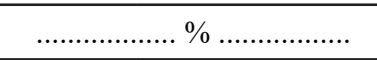 } \\
\hline $1^{\circ}$ ano $^{2}$ & $3,57 \mathrm{c}$ & $6,52 \mathrm{~b}$ & $0,0 \mathrm{~b}$ & $1,85 \mathrm{~b}$ & $45,52 \mathrm{~b}$ \\
\hline 0 & $4,27 \mathrm{~b}$ & $8,54 \mathrm{a}$ & $0,0 \mathrm{~b}$ & $2,97 \mathrm{a}$ & $49,95 \mathrm{a}$ \\
\hline 50 & $4,37 \mathrm{~b}$ & $8,11 \mathrm{a}$ & $0,02 \mathrm{ab}$ & $2,95 \mathrm{a}$ & $45,48 \mathrm{~b}$ \\
\hline 75 & $4,2 \mathrm{~b}$ & $8,54 \mathrm{a}$ & $0,07 \mathrm{ab}$ & $2,92 \mathrm{a}$ & $49,94 \mathrm{a}$ \\
\hline 100 & $4,8 \mathrm{a}$ & $8,55 \mathrm{a}$ & $0,10 \mathrm{a}$ & $2,87 \mathrm{a}$ & $43,42 \mathrm{~b}$ \\
\hline Teste F & $0,0 * *$ & $0,0 * *$ & $0,01 *$ & $0,0 * *$ & $0,0 * *$ \\
\hline CV (\%) & 8,67 & 8,88 & 208,3 & 11,8 & 7,69 \\
\hline
\end{tabular}

${ }^{1}$ Adubação $100 \%$ referente a $400 \mathrm{~kg} \mathrm{ha}^{-1}$ de $05-25-15+223 \mathrm{~kg} \mathrm{ha}^{-1}$ de uréia em cobertura; 2referente ao resultado obtido no final do primeiro ano de uso do biofertilizante na dosagem de $150 \mathrm{~L} \mathrm{ha}^{-1}$. *médias seguidas pela mesma letra na coluna, não diferem entre si pelo teste de Tukey a 5\% de probabilidade. CV: coeficiente de variação;3resultado com uso da dosagem de $150 \mathrm{~L} \mathrm{ha}^{-1}$ no primeiro ano.

O efeito do biofertilizante na disponibilização do P no solo pode ser observado na tabela 2, onde os valores finais podem estar associados a mineralização do P-orgânico contido neste produto. Em todos os tratamentos avaliados, os valores de P-Mehlich apresentaram-se maior que no primeiro ano, saindo de parâmetros considerados muito baixos para valores considerados médios no tratamento com 100\% da adubação (Souza \& Lobato, 2004). Indicando que o biofertilizante foi eficiente no aumento da atividade microbiana para a solubilização do fosfato e liberação do nutriente para o complexo de troca do solo.

Os incrementos nos teores de MO no solo com a aplicação do biofertilizante não influenciaram os teores de $\mathrm{N}$ no tecido foliar. Ao considerar que o teor de $\mathrm{N}$ adequado para a cultura do milho situado entre 28,0 a $35,0 \mathrm{~g} \mathrm{~kg}^{-1}$ (Malavolta et al., 2006), as plantas não estavam adequadamente nutridas, o que foi observado em todos os tratamentos (Tabela 3).
Para o P a concentração foliar, com a aplicação do biofertilizante no solo, em todos os tratamentos apresentam-se abaixo dos níveis considerados adequados (2,5 a 4,0 $\mathrm{g} \mathrm{kg}^{-1}$ ) para o milho (Malavolta et al., 2006), sendo que os teores do $\mathrm{P}$, no segundo ano de aplicação do biofertilizante, não diferiram entre as diferentes doses de adubação química aplicada. Como os teores do P no solo apresentaram aumento linear com o aumento da adubação química, nota-se uma menor absorção do nutriente o que diminui a exportação. A não-resposta à absorção do $\mathrm{P}$, pode estar associada a presença de $\mathrm{P}$ não ou lentamente disponíveis e a aplicação do biofertilizante superficial, nas entrelinhas, o que pode ter dificultado a absorção, já que o $\mathrm{P}$ se move por difusão no solo.

Os teores de $\mathrm{K}$ foram considerados adequados (17,0 a 30,0 $\mathrm{g} \mathrm{kg}^{-1)}$ para o milho (Malavolta et al., 2006), em todos os tratamentos, com maior valor absoluto para o tratamento com redução de $25 \%$ no fornecimento do adubo químico. $\mathrm{O}$ maior acúmulo de $\mathrm{K}$ no solo no 
tratamento sem adubação química (Tabela 3) e as menores concentrações observadas na folha, destacam novamente a menor capacidade de absorção das plantas, não ocorrendo a absorção não ocorre a extração e o nutriente se mantém no solo. Quanto à sua exportação com a colheita, as tendências observadas para o $\mathrm{N}$ e $\mathrm{P}$ foram, também, registradas para o $\mathrm{K}$, em que os maiores teores foliares resultaram na maior exportação de nutrientes.

Tabela 3 - Concentração foliar de nutrientes na cultura do milho após o uso de diferentes dosagens de adubação química e de biofertilizante, $150 \mathrm{~L} \mathrm{ha}^{-1}$, na safra 2017/2018

\begin{tabular}{cccccc}
\hline \multirow{2}{*}{$\%$ adubação } & \multicolumn{5}{c}{$\mathrm{g} \mathrm{kg}^{-1}$} \\
\cline { 2 - 6 } & $\mathrm{N}$ & $\mathrm{P}$ & $\mathrm{K}$ & $\mathrm{Ca}$ & $\mathrm{Mg}$ \\
\hline 0 & $21,3 \mathrm{a}$ & $1,32 \mathrm{a}$ & $22,82 \mathrm{~b}$ & $8,57 \mathrm{ab}$ & $3,97 \mathrm{a}$ \\
50 & $22,98 \mathrm{a}$ & $1,45 \mathrm{a}$ & $28,25 \mathrm{a}$ & $9,72 \mathrm{ab}$ & $4,12 \mathrm{a}$ \\
75 & $21,12 \mathrm{a}$ & $1,47 \mathrm{a}$ & $28,9 \mathrm{a}$ & $10,93 \mathrm{a}$ & $4,32 \mathrm{a}$ \\
100 & $23,1 \mathrm{a}$ & $1,42 \mathrm{a}$ & $28,15 \mathrm{a}$ & $10,60 \mathrm{ab}$ & $3,95 \mathrm{a}$ \\
\hline Teste $\mathrm{F}$ & $0,8 \mathrm{~ns}$ & $0,33 * *$ & $0,02 *$ & $0,06 \mathrm{~ns}$ & $0,68 \mathrm{~ns}$ \\
$\mathrm{CV}(\%)$ & 16,63 & 8,16 & 8,81 & 11,05 & 11,73 \\
\hline
\end{tabular}

\begin{tabular}{ccccc}
\hline \multirow{2}{*}{ \% adubação } & \multicolumn{4}{c}{$\mathrm{mg} \mathrm{kg}^{-1}$} \\
\cline { 2 - 5 } & $\mathrm{Cu}$ & $\mathrm{Fe}$ & $\mathrm{Mn}$ & $\mathrm{Zn}$ \\
\hline 0 & $7,62 \mathrm{~b}$ & $128,52 \mathrm{a}$ & $18,6 \mathrm{a}$ & $15,77 \mathrm{a}$ \\
50 & $8,57 \mathrm{ab}$ & $134,75 \mathrm{a}$ & $20,72 \mathrm{a}$ & $14,67 \mathrm{ab}$ \\
75 & $7,97 \mathrm{ab}$ & $138,72 \mathrm{a}$ & $20,67 \mathrm{a}$ & $12,2 \mathrm{~b}$ \\
100 & $9,55 \mathrm{a}$ & $149,42 \mathrm{a}$ & $22,37 \mathrm{a}$ & $12,97 \mathrm{ab}$ \\
Teste F & $0,03 *$ & $0,45 \mathrm{~ns}$ & $0,18 \mathrm{~ns}$ & $0,02 *$ \\
$\mathrm{CV}(\%)$ & 9,62 & 13,07 & 10,55 & 10,53 \\
\hline
\end{tabular}

${ }^{1}$ Adubação $100 \%$ referente a $400 \mathrm{~kg} \mathrm{ha}^{-1}$ de $05-25-15+223 \mathrm{~kg} \mathrm{ha}^{-1}$ de uréia em cobertura; 2referente ao resultado obtido no final do primeiro ano de uso do biofertilizante na dosagem de $150 \mathrm{~L} \mathrm{ha}^{-1}$. *médias seguidas pela mesma letra na coluna, não diferem entre si pelo teste de Tukey a $5 \%$ de probabilidade, ns: não significativo. CV: coeficiente de variação.

Observa-se aumento nos teores de Ca, no segundo ano do uso do biofertilizante, na análise foliar. Os valores de Ca na matéria seca foliar foram considerados excessivos, e crescem linearmente em $0,023 \mathrm{~g} \mathrm{~kg}^{-1}$, para cada $\mathrm{kg}$ de adubo químico adicionado no solo até a dosagem com $75 \%$ da adubação recomendada. A concentração de $\mathrm{Ca}$ pode estar associada ao teor encontrado no biofertilizante, já que não foi realizada calagem no segundo ano, ou seja, a elevação do teor de Ca trocável no solo resultou em maior absorção deste nutriente.

As maiores concentrações de $\mathrm{Ca}$ e $\mathrm{Mg}$ na folha resultaram na maior produtividade da cultura. Os teores de $\mathrm{Mg}$ foram considerados excessivos no tratamento com 50 e $75 \%$ da adubação química e adequado nos demais tratamentos. Como o maior valor no solo foi observado na testemunha, sem adubação química, pressupõem-se que a menor absorção levou ao maior residual no solo do nutriente. Pelos resultados foliares (Tabela 3) pode-se observar que o tratamento com $75 \%$ da adubação recomendada na presença do biofertilizante consegue suprir as necessidades nutricionais da cultura para $\mathrm{K}, \mathrm{Ca}$ e $\mathrm{Mg}$, com deficiência nutricional para $\mathrm{N}$ e $\mathrm{P}$ em todas as dosagens de adubação química utilizada.

Santos \& Nogueira (2012) enfatizam que o biofertilizante permite reciclar nutrientes e manter a produtividade do solo em níveis adequados pela presença de macro e micronutrientes disponíveis. Para os micronutrientes analisados na folha, o $\mathrm{Cu}$ e Fe em todos os tratamentos foram considerados dentro da faixa adequada para a cultura, para o Mn somente o tratamento sem adubação foi considerado abaixo dos teores adequados de acordo com Malavolta et al. (2006). 
Para o $\mathrm{Zn}$ todos os tratamentos no segundo ano foram considerados abaixo da faixa adequada (20,0 a 40,0 $\mathrm{mg} \mathrm{kg}^{-1}$ ). A disponibilidade pode estar relacionada ao $\mathrm{pH}$ do solo, onde a elevação de uma unidade de $\mathrm{pH}$ provoca diminuição de 100 vezes na concentração do $\mathrm{Zn}$ na solução do solo. O antagonismo de absorção de $\mathrm{P}$ e Zn é destacado na literatura (Malavolta et al., 2006), observa-se que para as menores concentrações de $\mathrm{P}$ se obteve as maiores concentrações de $\mathrm{Zn}$ na folha.

Além da fertilidade do solo e da capacidade de absorção de nutrientes, outro fator que pode ter influenciado o desempenho da cultura foi a precipitação. $\mathrm{O}$ volume de precipitação pluviométrica acumulada durante o cultivo foi de $1.048,4 \mathrm{~mm}$, superior ao volume mínimo exigido

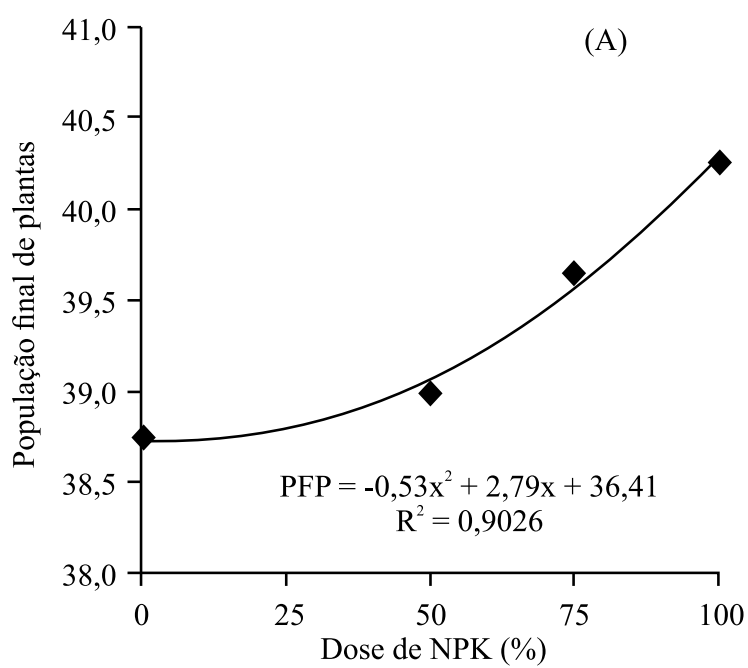

pela cultura de $600 \mathrm{~mm}$, porem má distribuída durante o ciclo da cultura. O início do florescimento ocorreu 60 dias após emergência com o aparecimento da inflorescência masculina. Os dados climáticos indicam que a precipitação pluviométrica foi inadequada no início do florescimento da cultura, ocasionando um período de déficit hídrico a planta e contribuindo negativamente para a produtividade final de grãos.

A população final de plantas não foi influenciada pela aplicação de doses de NPK, o que garante que os demais parâmetros agronômicos avaliados no presente estudo não foram influenciados pela população de plantas. $\mathrm{Na}$ análise de regressão houve ajuste ao modelo quadrático (Figura 1A).

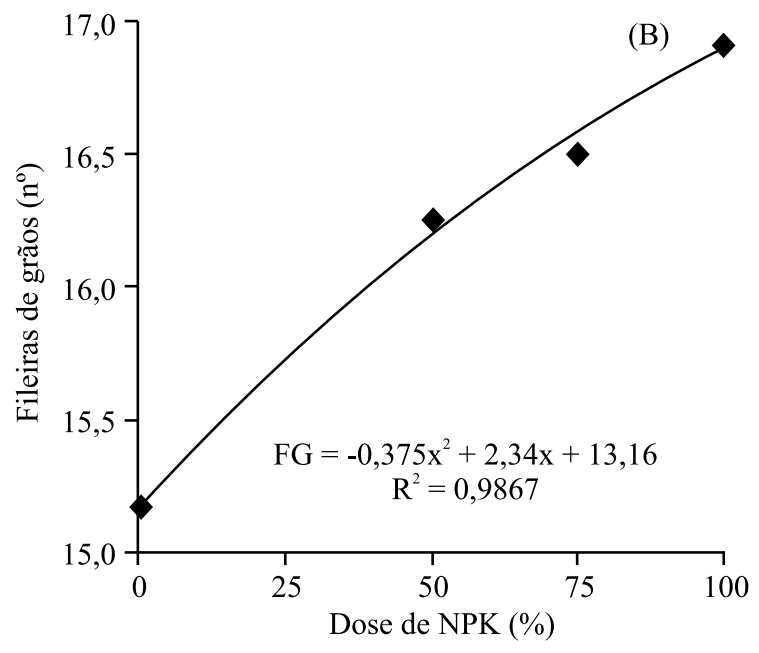

Figura 1 - População final de plantas (A) e número de fileiras de grãos (B) de milho em função da aplicação de doses de adubação NPK em semeadura e cobertura com aplicação de biofertilizante na cultura do milho primeira safra, Anápolis, GO, Brasil (2017/18).

O comprimento de espigas entre os tratamentos $75 \%$ e $100 \%$ não apresentaram diferença significativa, o que pode estar atribuído à aplicação do biofertilizante na cultura. Tal resultado não era esperado já que o tratamento $100 \%$ apresenta maior disponibilidade de nutrientes, favorecendo o crescimento de espigas, contrariando o que foi observado por Kappes et al. (2013), que obteve aumento no comprimento de espigas conforme se elevou as doses de $\mathrm{N}$ na cultura. Quanto ao número de fileira de grãos (FG) os tratamentos $75 \%$ e $100 \%$ também não apresentaram diferença estatística o que pode ser explicado principalmente pelo diâmetro de espiga terem sido os fatores com maior média. De acordo com Ohland et al. (2005) o número de fileiras de grãos correlaciona positivamente com o diâmetro de espigas.

A elevação das doses de adubação química NPK proporcionou aumento linear do comprimento de espigas (Figura 2A), estando segundo Kappes et al. (2009) diretamente relacionada ao aumento produtivo da cultura. Estes resultados corroboram com Rolim et al. (2018), indicando que os nutrientes fornecidos para a cultura do milho foram efetivamente absorvidos e utilizados para o crescimento da espiga.

A variável diâmetro de espigas (DE) sofreu influência somente no tratamento sem adubação, possuindo 
a menor média. Os demais tratamentos não se diferenciaram estatisticamente. $\mathrm{O}$ aumento nas doses de adubação química proporcionou au $\neg$ mento linear do diâmetro de espigas (Figura 2B).

No número de grãos por fileira (GF), os tratamentos com $75 \%$ e $100 \%$, da adubação química não se diferenciaram estatisticamente, enquanto que na testemunha e no tratamento com $50 \%$, da adubação química recomendada, os resultados foram inferiores e contribuíram para a redução da produtividade final. $\mathrm{O}$ número de grãos por fileira em função da dose de adubação química (Figura 2C), verificou-se que o melhor modelo de regressão foi o linear, enquanto que para o número de fileiras de grãos (Figura 2B) o modelo mais representativo foi o polinomial de segunda ordem.

A massa de mil grãos (MMG) aumentou significativamente à medida em que ocorreu o aumento na disponibilidade nutricional, ajustando-se ao modelo de equação linear pela análise de regressão (Figura 2D).

Verifica-se que a maior média para a variável produtividade foi obtida no plantio realizado com $100 \%$ da adubação recomendada para a cultura, sem diferença significativa para o tratamento com $75 \%$ da dose recomendada (Figura 2E). A aplicação da dose de $100 \%$ de NPK proporcionou uma produtividade de $12.483,78 \mathrm{~kg} \mathrm{ha}^{-1}$ de grãos de milho, valor este $123,44 \%$ superior ao menor valor obtido, sem uso de adubação e inferior aos observados por Kunesk et al. (2017), trabalhando com a mesma variedade, que obteve produtividade de $14.659 \mathrm{~kg} \mathrm{ha}^{-1}$.

A adubação com NPK apresentou resposta positiva, aumentando os componentes massa de 1.000 grãos e a produtividade de grãos. O tratamento $100 \%$ da adubação obteve a maior média. Isto se deu em função da maior disponibilidade de nutrientes promovido pela maior dose de adubação. Já o tratamento $75 \%$ da adubação neste item foi inferior ao tratamento $100 \%$, o que pode ser explicado pelas reservas de nutrientes terem sido consumidos para crescimento da espiga e para o número de grãos por espiga. Em contrapartida o tratamento $75 \%$ não se diferiu do tratamento $50 \%$. A testemunha apresentou a menor média entre os tratamentos. Resultado semelhante ocorreu com Silva et al. (2014) que também verificou acréscimo de produção em função do aumento na adubação nitrogenada e fosfatada.

A produtividade de grãos apresentou aumento nas médias conforme se elevou as doses de adubação NPK (Figura 2E), porém não houve diferença entre os tratamentos $75 \%$ e $100 \%$. Os resultados diferem de Silva et al. (2017), que ao avaliar a resposta do milho a doses NPK em semeadura e cobertura obteve o aumento produtivo conforme elevou-se as doses de fertilizantes.

Kappes et al. (2013) observou aumento da produtividade da cultura do milho com aumento das doses de $\mathrm{N}$ em cobertura, enquanto que Valderrama et al. (2011), avaliando o efeito de doses de adubação NPK na cultura do milho irrigado obteve incremento linear na produtividade da cultura conforme elevou-se a aplicação de N, enquanto que a adubação fosfatada e potássica não influenciou de forma isolada na produtividade de grãos. Os resultados observados neste experimento apresentam grande potencial do biofertilizante com redução de adubação NPK. Destaque deve ser dado ao tratamento com $75 \%$ da adubação e aplicação do biofertilizante que apresentou resultados semelhantes ao tratamento com $100 \%$ da dose de adubação NPK para os componentes de produção analisadas neste experimento com exceção da massa de mil grãos.

\section{CONCLUSÕES}

A aplicação do biofertilizante via solo permite melhorar o estado nutricional e produtivo da cultura do milho, em plantio direto no Cerrado, com reflexos positivos na melhora da fertilidade do solo. Podendo-se, também, reduzir os impactos ambientais com a redução da adubação química.

Ocorre maior acúmulo de nutrientes nas plantas do tratamento com $75 \%$ da adubação química e aplicação do biofertilizante o que supre a menor dose de adubação aplicada, refletindo na produtividade.

O tratamento $100 \%$ da dose de adubação química com aplicação do biofertilizante apresentou a maior produtividade entre os tratamentos, sendo semelhante estatisticamente ao tratamento $75 \%$, mesmo com maior disponibilidade de nutrientes.

Novos estudos devem ser realizados a fim de verificar se o uso contínuo promove melhorias gradativas na fertilidade dos solos do Cerrado.

\section{AGRADECIMENTOS}

Ao Centro Universitário de Anápolis UniEvangélica, pela bolsa de Iniciação Científica (PIBIC) concedida, bem como ao suporte técnico, laboratorial e teórico disponibilizado pela instituição. À Microgeo® pela disponibilização do produto. 

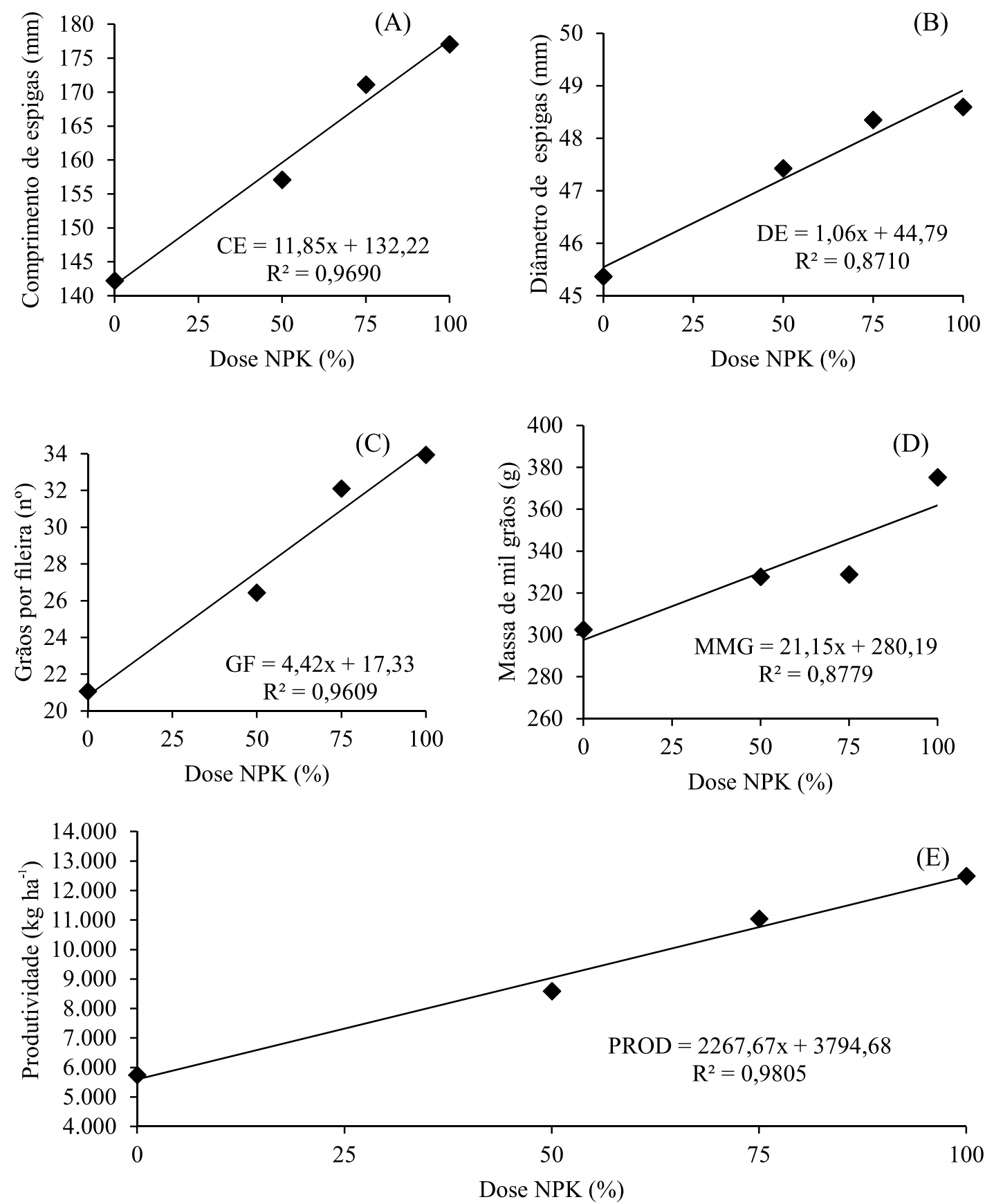

Figura 2 - Comprimento de espiga (A), diâmetro de espigas (B), número de grãos por fileira (C), massa de mil grãos (D) e produtividade (E) de milho em função da aplicação de doses de adubação NPK em semeadura e cobertura com aplicação de biofertilizante na cultura do milho primeira safra, Anápolis, GO, Brasil (2017/18). 


\section{LITERATURA CITADA}

ALENCAR, T. L.; CHAVES, A. F.; SANTOS, C. L. A. et al. Atributos físicos de um Cambissolo cultivado e tratado com biofertilizante na Chapada do Apodi, Ceará. Revista Brasileira de Ciência do Solo, v. 39, n. 3, 2015.

ARAUJO, F. F.; SANTOS JÚNIOR, J. D. Desenvolvimento e nutrição de milho em solo degradado biofertilizado com fosfato natural, enxofre e Acidithiobacillus. Revista Caatinga, v. 22, n. 1, 2009.

BARROS, L.E.O.; LIBERALINO FILHO, J. Composto orgânico sólido e em suspensão na cultura do feijãomungo-verde (Vigna radiata L, Wilkzeck). Revista Verde, Mossoró, v.3, n.1, p.114-122, 2008.

BELLINI, G.; SCHMIDT FILHO, E.; MORESKI, H. M. Influência da aplicação de um fertilizante biológico sobre alguns atributos físicos e químicos de solo de uma área cultivada com arroz (Oriza sativa). Revista em Agronegócio e Meio Ambiente, v. 6, n. 2, 2012.

FERREIRA, D. F. Sisvar: A Guide for its Bootstrap procedures in multiple comparisons. Ciência e Agrotecnologia, Lavras-MG, v. 38, n. 2, p. 109-112, 2014.

KAPPES, C.; CARVALHO, M. A. C.; YAMASHITA, O. $\mathrm{M}$. et al. Influência do nitrogênio no desempenho produtivo do milho cultivado na segunda safra em sucessão à soja. Pesquisa Agropecuária Tropical, Goiânia, v. 39, p. 251259, 2009.

KAPPES, C.; ARF, O.; ANDRADE, J. A. D. C. Produtividade do milho em condições de diferentes manejos do solo e de doses de nitrogênio. Revista Brasileira de Ciência do Solo, p. 1310-1321, 2013.

KUNESKI, H. F.; SANGOI, L.; COELHO, A. E. et al. Desempenho Agronômico de Híbridos de Milho no Alto Vale do Itajaí-SC. 14 ${ }^{\mathrm{a}}$ Jornada de Pós-Graduação e Pesquisa, Congrega Urcamp-2017, p. 1146-1159, 2017.

LIMA, J. G. A.; VIANA, T. V. A.; SOUSA, G. G. et al. Crescimento inicial do milho fertirrigado com biofertilizante. Revista Agropecuária Científica no Semiárido, v.8, n.1, p.39-44, 2012.

MALAVOlTA, E.; VITTI, G. C.; OliVEIRA, S. A. Avaliação do estado nutricional das plantas - princípios e aplicações. Piracicaba, Potafos, 1989. 201p.

MALAVOLTA, E.; MORAES, M. F.; LAVRES JÚNIOR, J. et al. Micronutrientes e metais pesados essencialidade e toxidez. Cap. 4. Ciência, agricultura e sociedade. Brasília: Embrapa Informação Tecnológica, p. 117-154, 2006.
OHLAND, R. A. A.; SOUZA, L. C. F.; HERNANI, L. C. et al. Culturas de cobertura do solo e adubação nitrogenada no milho em plantio direto. Ciência e Agrotecnologia, Lavras, v. 29, p. 538-544, 2005.

REBOUÇAS NETO, M. D. O.; CAMPOS, J. R.; VERAS, C. L. et al. Crescimento inicial do milho sob diferentes concentrações de biofertilizante bovino. Cadernos Cajuína, v. 1, n. 3, p. 4-14, 2016.

RODRIGUES, V. N.; VON PINHO, R. G.; PAGLIS, C. M. et al. Comparação entre métodos para estimar a produtividade de grãos de milho. Ciência e Agrotecnologia, Lavras, v. 29, n. 1, p. 34-42, 2005.

ROLIM, R. R.; PINTO, A. A.; CAMARA, F. T. et al. Produtividade e rentabilidade do milho em função do manejo da adubação, em regime de sequeiro, na região do Cariri-CE. Revista Científica Rural, v. 20, n. 1, p. p. 204221, 2018.

SANTOS, I. A.; NOGUEIRA, L. A. H. Estudo energético do esterco bovino: seu valor de substituição e impacto da biodigestão anaeróbia. Revista Agrogeoambiental, Pouso Alegre, v. 4, n. 1, p. 41-49, abr. 2012.

SANTOS, J. L. G.; GONDIM, A. R. O.; LIMA NETO, J. V. et al. Cultivo da cenoura submetida à aplicação de doses de biofertilizante. Revista Verde de Agroecologia e Desenvolvimento Sustentável, v.12, n.1, p.55-60, 2017.

SEDIYAMA, M. A.; SANTOS, M. R.; VIDIGAL, S. M. O. P. et al. Nutrição e produtividade de plantas de pimentão colorido, adubadas com biofertilizante de suíno. Revista Brasileira de Engenharia Agricola e Ambiental-Agriambi, v. 18, n. 6, 2014.

Silva, J. C. P. M.; MOTTA, A. C. V.; PAUleTti, V. et al. Esterco líquido de bovinos leiteiros combinado com adubação mineral sobre atributos químicos de um Latossolo Bruno. Revista Brasileira de Ciência do Solo, v. 32, n. 6, 2008.

SILVA, F. C. (Ed.) Manual de análises químicas de solos, plantas e fertilizantes. Embrapa Informação Tecnológica. Rio de Janeiro: Embrapa Solos, 2009.

SILVA, G. F.; OLIVEIRA, F. H.; PEREIRA, R. G. et al. Doses de nitrogênio e fósforo para produção econômica de milho na Chapada do Apodi, RN. Revista Brasileira de Engenharia Agricola e Ambiental-Agriambi, v. 18, n. 12, 2014.

SILVA, J. G.; NASCIMENTO, J. M. L.; SANTOS, M. R. B. et al. Archivos de Zootecnia, v.64. n.248, p.323-329, 2015. 
SILVA, W. C.; MOTA, A. M. D.; DA SILVA, C. S. et al. Resposta do milho a doses de NPK na semeadura e de N em cobertura em sistema de plantio convencional. Revista Espacios, v.38, n. 36, 2017.

SOUSA, D. M. G.; LOBATO, E. (Ed.) Cerrado: correção do solo e adubação. 2. ed. Brasília, DF: Embrapa Informação Tecnológica, 2004. 416p.
VALDERRAMA, M.; BUZETTI, S.; BENETT, C. G. S. et al. Fontes e doses de NPK em milho irrigado sob plantio direto. Pesquisa Agropecuária Tropical, p. 254-263, 2011.

Recebido para publicação em 24/05/2019 e aprovado em 20/12/2019. 